\title{
HUMAN MEIOSIS IV. THE ELIMINATION OF SYNAPTONEMAL COMPLEX FRAGMENTS FROM METAPHASE I BIVALENTS OF HUMAN SPERMATOCYTES
}

\author{
by \\ SØREN W. RASMUSSEN and PREBEN B. HOLM \\ Department of Physiology, Carlsberg Laboratory, \\ Gamle Carlsberg Vej 10, DK-2500 Copenhagen Valby
}

Keywords: Chiasmata, kinetochore, polycomplex, centromere

\begin{abstract}
Three dimensional reconstructions of 3 prometaphase I, 6 methaphase I and 2 anaphase I cells from 4 normal human males have been performed. At prometaphase I, 45, 36 and 32 fragments of synaptonemal complexes are present, of which 42, 22 and 23 were located within the bivalents. At metaphase l, the synaptonemal complex fragments are expelled from the bivalents, either as apparently intact fragments or as rearranged subunits of the synaptonemal complex which form small synaptonemal polycomplexes at the border of the bivalents or in the nucleoplasm. At early anaphase $\mathrm{I}$, the bivalents were almost completely devoid of synaptonemal complex fragments. The possible relationship between these fragments and chiasmata is discussed. The changes in the ultrastructure of the bivalents during these stages is described. At prometaphase each of the four chromatids of a bivalent possesses a kinetochore.
\end{abstract}

\section{INTRODUCTION}

The ultrastructure of the synaptonemal complex from the formation of lateral components in leptotene, during the pairing of homologous chromosomes in zygotene until completion of synaptonemal complex formation at pachytene has been analyzed in detail in human spermatocytes $(6,7,8,18)$ as well as in a number of other organisms (reviews $4,13,25$ ). In organisms with chiasmatic meiosis, the bulk of the synaptonemal complexes are shed from the bivalents at the beginning of diplotene, leaving behind short stretches of complex between the homologues $(3,10,12,20,22,24,27)$. It has been suggested that these fragments are the ultrastructural counterparts of chiasmata (synaptonemal complex chiasmata) (24), and that they may provide a temporal physical stabilization of the sites where crossing over has occurred. Towards the end of diplotene the fragments have been reported to disappear $(3,20,22,24)$, and it has been suggested that they are replaced by stable 
chromatin bridges $(20,24,26)$. Retained synaptonemal complex fragments have, however, been reported in the grasshopper, Corthippus longicornis (12), in the pigeon (15), and in human spermatocytes $(7,21)$, either in the form of small fragments of apparently normal synaptonemal complexes or as small aggregates of rearranged synaptonemal complexes.

In organisms without crossing over such as diploid Bombyx mori females $(16,17)$ or with achiasmatic meiosis as the males of Bolbe nigra (2) the synaptonemal complexes are retained between the homologues up to metaphase I, in Bombyx in a modified form and in Bolbe apparently unaltered. In Bombyx females it has been suggested that the modified synaptonemal complexes serve as a substitute for the action of the crossover sites in order to preserve the coorientation of the two homologues, which is a prerequisite for a proper disjunction of the homologous chromosomes at anaphase $\mathrm{I}$.

The present report is a continuation of our previous analysis of the synaptonemal complex fragments in human spermatocytes from prometaphase I to and including anaphase I. Furthermore, it describes changes in ultrastructure of the bivalents and their kinetochores during the prometaphase-anaphase I interval.

\section{MATERIALS AND METHODS}

Testicular biopsies were obtained from three normal and fertile men undergoing vasectomy. The biopsies were obtained through the courtesy of dr. J. LindenberG, Dept. of Surgery K, Frederiksberg Hospital, Copenhagen. Detailed descriptions of the zygotene and pachytene stages in the spermatocytes of these men have been presented in previous publications (cases 3-5 in 6,18). In addition, a testicular biopsy was obtained from one azoospermic man (case $l$ in 6) through the courtesy of dr. N. E. SKaKKE-
BÆK, Laboratory of Reproductive Biology, University Dept. of Obstetrics and Gynecology, Rigshospitalet, Copenhagen. The patient lacked ductus deferens and the main part of the epididymis was atrophic. Histological analysis revealed, however, a quantitatively normal spermatogenesis in the majority of the seminiferous tubules (SKAKKEBÆK, personal communication). The ultrastructure of the pachytene nuclei as well as the length, centromere index, and other structural characteristics of the bivalents were similar to that of the normal males (6). The prometaphase I cells (numbers 6, 18 and 19) are from case 1 , the metaphase I cells with the numbers 45,46 and 51 are from case 5 , and numbers 76,78 and 79 from case 4 . The early anaphase I cells with numbers 52 and 53 are from case 3 . The procedures used for fixation, embedding, serial sectioning and reconstruction have been presented in previous publications $(6,18)$.

\section{RESULTS}

\subsection{General aspects}

The ultrastructural characteristics of cells in prometaphase and metaphase I are shown in Figures 1 and 4 . The chromatin of the bivalent arms is at prometaphase I relatively loose with electron transparent cavities, each bivalent possessing one region of heavily compacted centromeric heterochromatin (Figure 1), whereas the chromatin at metaphase I appears more uniformly condensed (Figure 4). Fragments of synaptonemal complexes were frequently found both in prometaphase and metaphase cells either embedded in the chromatin, located at the periphery of the bivalents, or free in the nucleoplasm (see section 3.2.).

A reconstruction of the bivalents of a prometaphase $I$ cell is shown in Figure 2. As seen in Figure $2 \mathrm{c}, 8$ of the 23 bivalents have fused into

\footnotetext{
Figure 1. Survey micrograph of a spermatocyte in prometaphase I (nucleus 18). The plane of sectioning is perpendicular to the spindle revealing only transverse and oblique sections of the microtubules. The chromatin of several bivalents is confluent (cf. Figure 2). The centromeric heterochromatin $(\mathrm{CH})$ can be identified by its higher electron density and more uniform appearance compared to the rest of the chromatin which contains electron transparent cavities. Three synaptonemal complex fragments (SC) are present in the section, one in the middle of a bivalent while the other two fragments are located at the border of a different bivalent. The insert is a higher magnification of the former SC fragment. ( $B a r=1 \mu \mathrm{m}$; insert: $B a r=0.2 \mu \mathrm{m}$ ).
} 


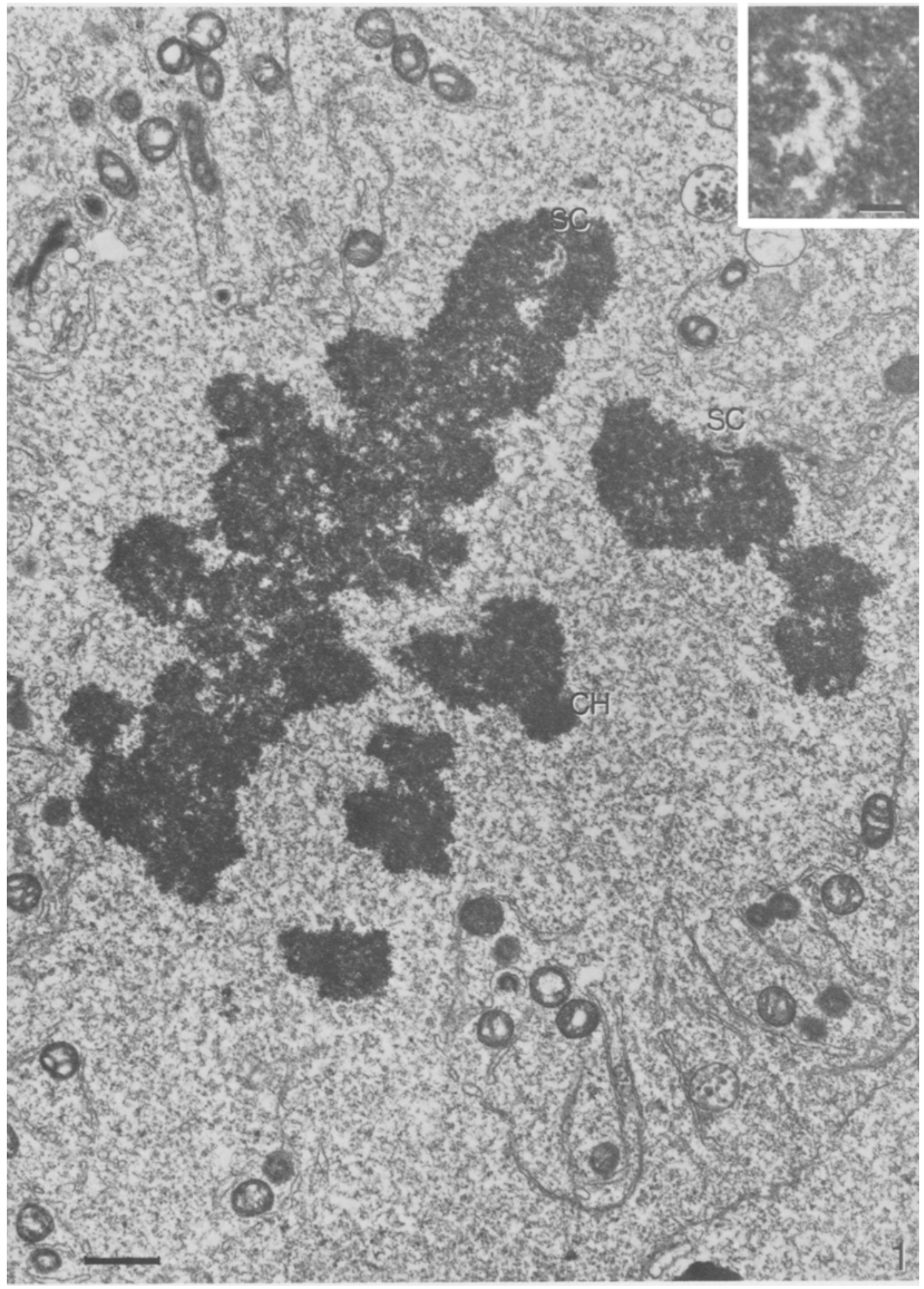




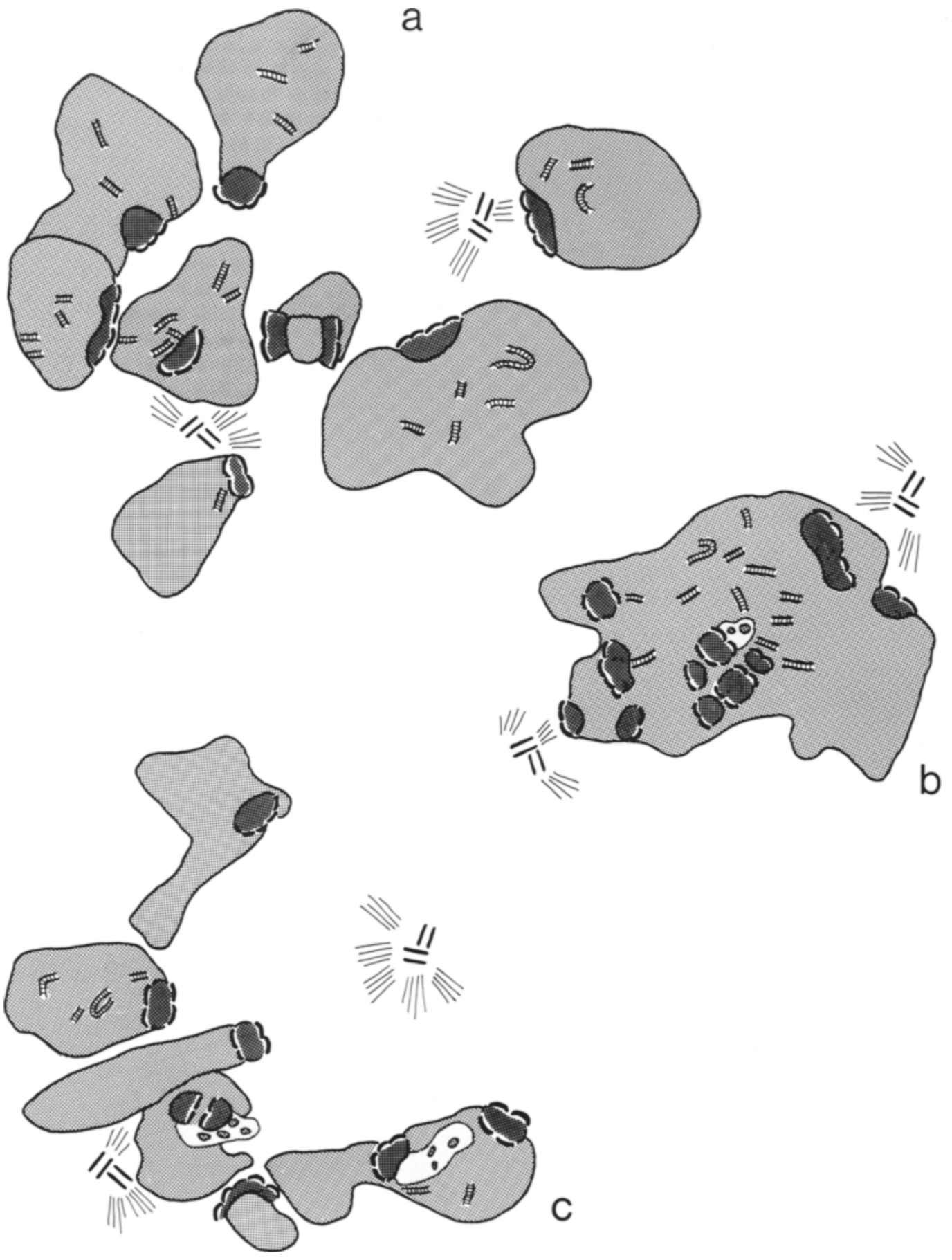

Figure 2. Complete reconstruction of a prometaphase I. At each pole one pair of centrioles is present. The centromeric heterochromatin is shown with a dark hatched signature and the diffuse centromeric heterochromatin of bivalents 1,9 and 16 with a lighter hatching. The kinetochores are shown with solid lines. Inside the chromatin, fragments of synaptonemal complexes are shown. The 8 bivalents depicted in Figure $2 b$ are too closely associated to allow an unambiguous tracing of the individual bivalents. 

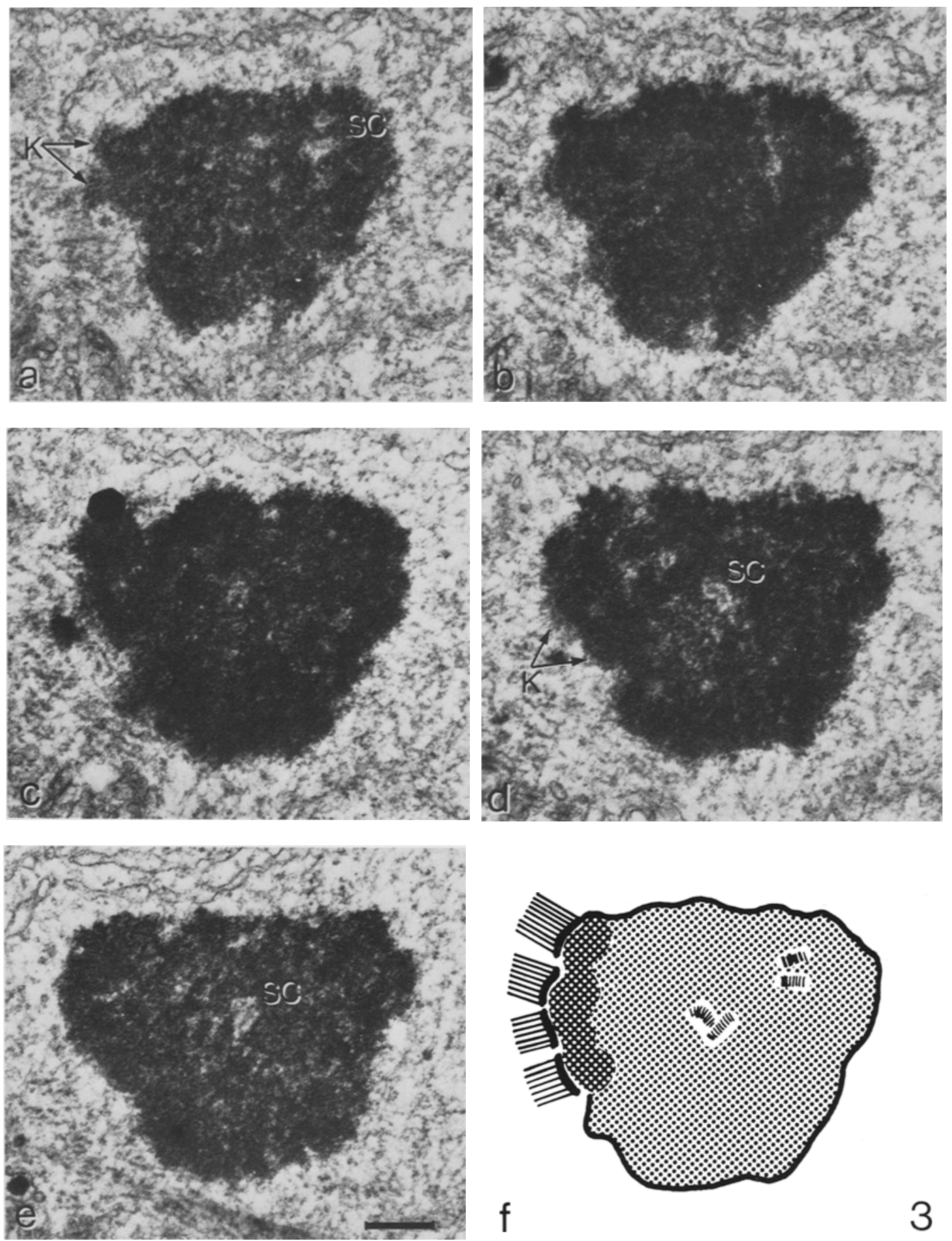

Figure 3. Five consecutive sections through a bivalent at prometaphase I (nucleus 6). A reconstruction of these sections is given in Figure $3 \mathrm{f}$ and a complete reconstruction of all bivalents of this cell is presented in Figure 2. The bivalent is located near the centrioles at one of the spindle poles. The two pairs of kinetochores $(\mathrm{K})$ can be seen, one in Figure $3 \mathrm{a}$ and one in Figure 3d. Each kinetochore is slightly curved and appears to be completely separated from the kinetochore of its sister chromatid as well as from the kinetochores of the homologous chromosome. The two pairs of kinetochores are oriented slightly different, the lower pair facing downwards in the micrographs. It is, however, not possible to establish whether microtubule connections exist between the two pairs of kinetochores and both centrioles. Four synaptonemal complex fragments (SC) are present in the bivalent. The centromeric heterochromatin is indicated by a darker hatching in Figure $3 \mathrm{f}$. $(\mathrm{Bar}=0.5 \mu \mathrm{m})$. 


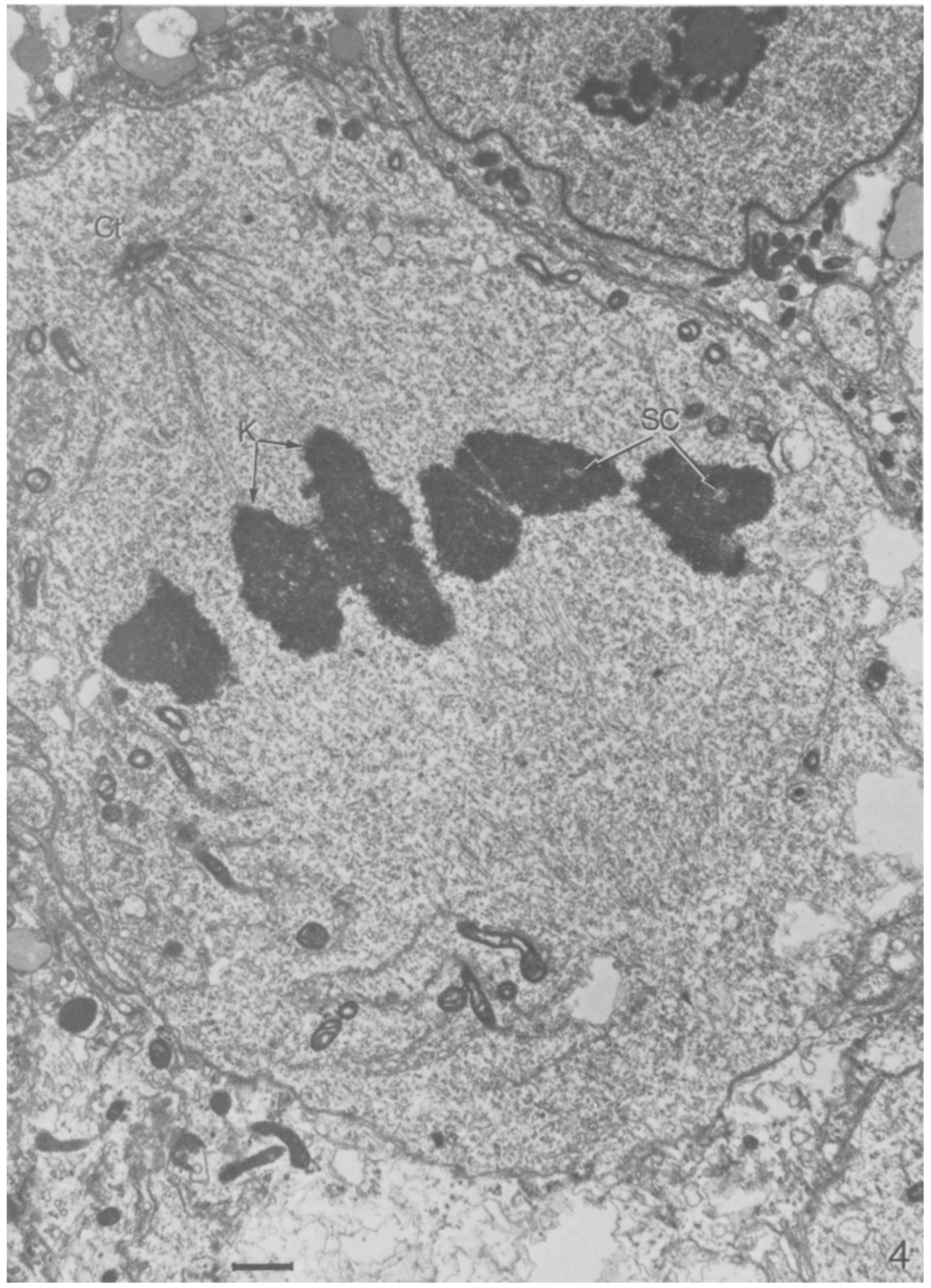

Figure 4, Survey micrograph of a spermatocyte at metaphase 1 (nucleus 45 ). The section includes one pair of centrioles $(\mathrm{Ct})$ and several bundles of microtubules spanning the entire distance between the kinetochores of the bivalents $(K)$ and the centrioles. The bivalents are organized into a metaphase plate with the kinetochores of the homologous chromosomes widely separated and facing towards opposite poles. Synaptonemal complex fragments (SC) are present in two of the bivalents. The chromatin of the bivalents is more condensed than at prometaphase (cf. Figure 1). (Bar $=1.0$ um). 
S. W. RASmussen \& P. B. Holm: Human meiosis IV
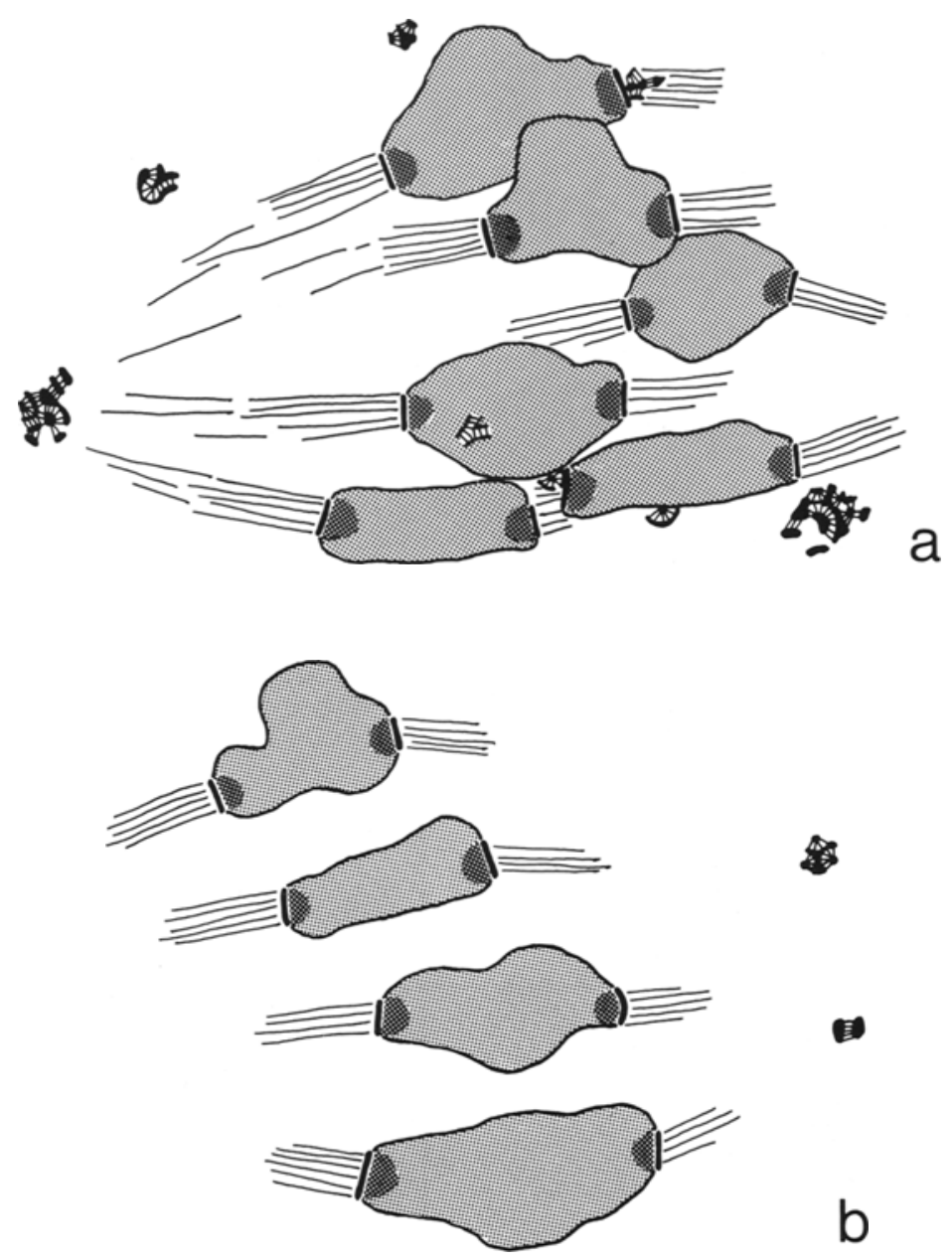

8

事

b

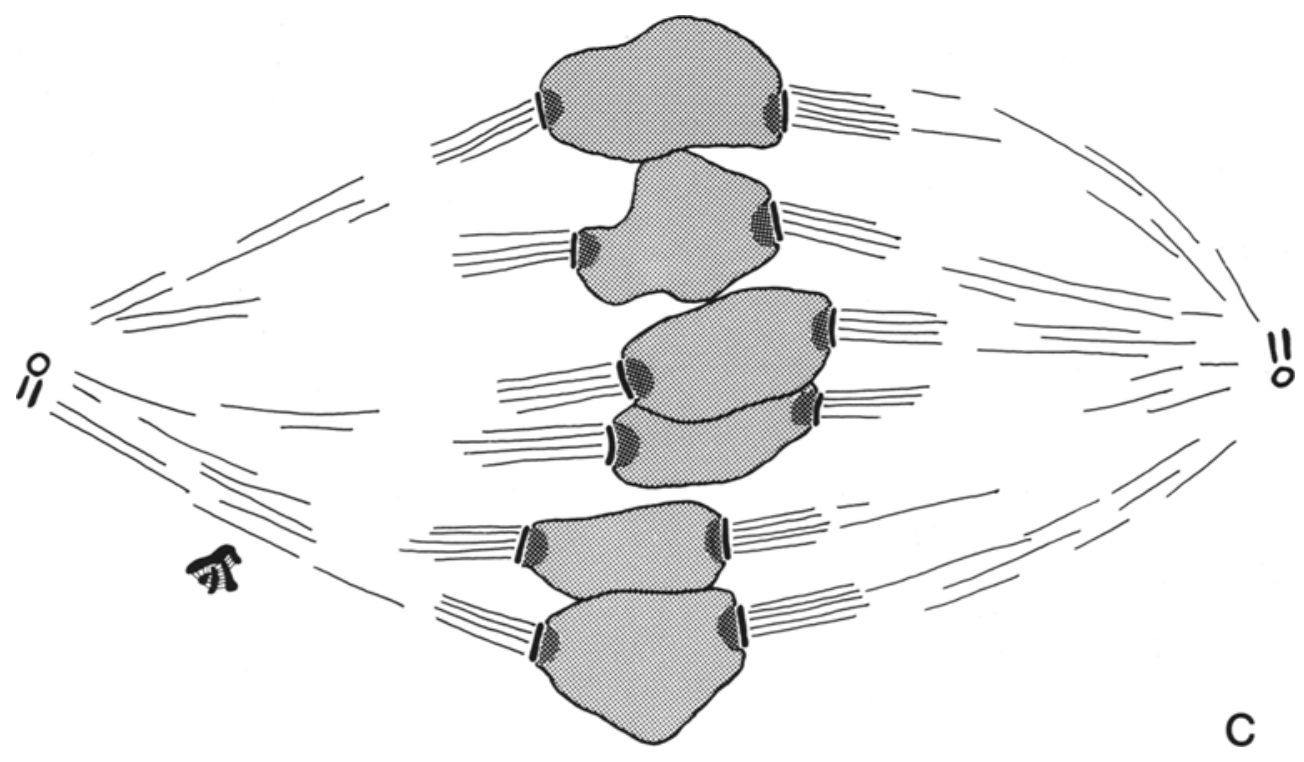




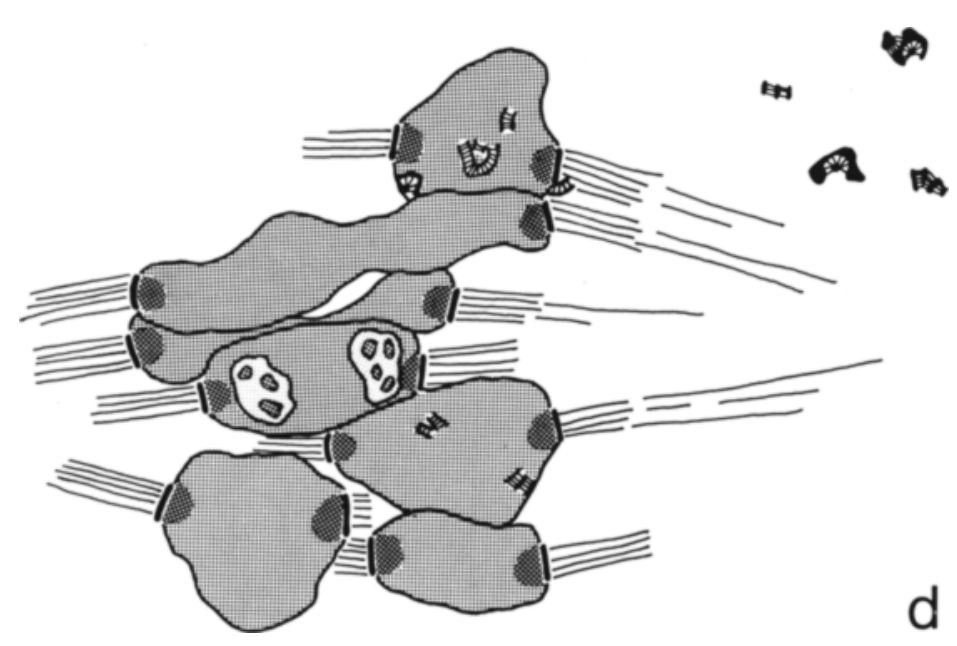

Figure 5. Reconstruction of the 23 bivalents at metaphase I (nucleus 45). The majority of the synaptonemal complex fragments have fused into small polycomplexes which are either located at bivalent borders or free in the nucleoplasm. The secondary constriction of bivalent 1 or 9 is recognizable in Figure 5d (lighter hatching). The kinetochores of the homologues are oriented towards opposite poles with continuous bundles of microtubules between the centrioles and kinetochores.

a continuous mass forming the metaphase plate thereby making an unambiguous tracing of the individual bivalents impossible. The remaining 15 bivalents shown in Figures $2 a-b$ are fully or partly separated, several of them being located close to the spindle pole. It was not possible to distinguish the two homologues of individual bivalents nor could the two sister chromatids of each homologue be identified. In most of the bivalents one region of centromeric heterochromatin could be recognized (Figures 2 and 3 ), either as a single spherical structure or as a bipartite dumbbell shaped region. Four kinetochores flank this region, each kinetochore being organized as a tripartite and generally crescent shaped disc. The kinetochore of the individual chromatid frequently appears to be separated from the kinetochore of the sister chromatid (Figure 3).

The spindle is at this stage well defined but it was not possible to trace the individual microtubules from kinetochores to centrioles. Therefore, it could not be ascertained whether the bivalents located in the vicinity of the centriole pairs were oriented in a unipolar or bipolar fashion. The tracings of the kinetochores shown in Figure 2 suggest, however, a bipolar orientation of most of the bivalents.
In the two other prometaphase I cells (nuclei 18 and 19) most of the bivalents were oriented in a bipolar fashion with separation of the two homologous centromere regions. Only in bivalents located near one of the poles was fusion of the centromeric heterochromatin still evident. In the metaphase plate several bivalents were closely associated, in all cases, however, the centromeric heterochromatin of the individual bivalents was fully individualized. This may indicate that these cells are more advanced than the one depicted in Figure 2.

At metaphase I all 23 bivalents are located in a metaphase plate, with the kinetochores of the homologues widely separated and facing toward opposite poles (Figures 4 and 5). The kinetochores of the two sister chromatids are confluent and form a straight laminated disc consisting of an outer layer of electron transparent material, an electron dense layer $15-20 \mathrm{~nm}$ in thickness and an electron transparent layer of similar thickness, (Figures 6, 8 and 9). As seen in Figure 9, the region of centromeric heterochromatin adjacent to the kinetochore possesses a higher electron density than the remainder of the centromeric heterochromatin.

Reconstruction of the two anaphase cells was hampered by the fact that the plane of section- 

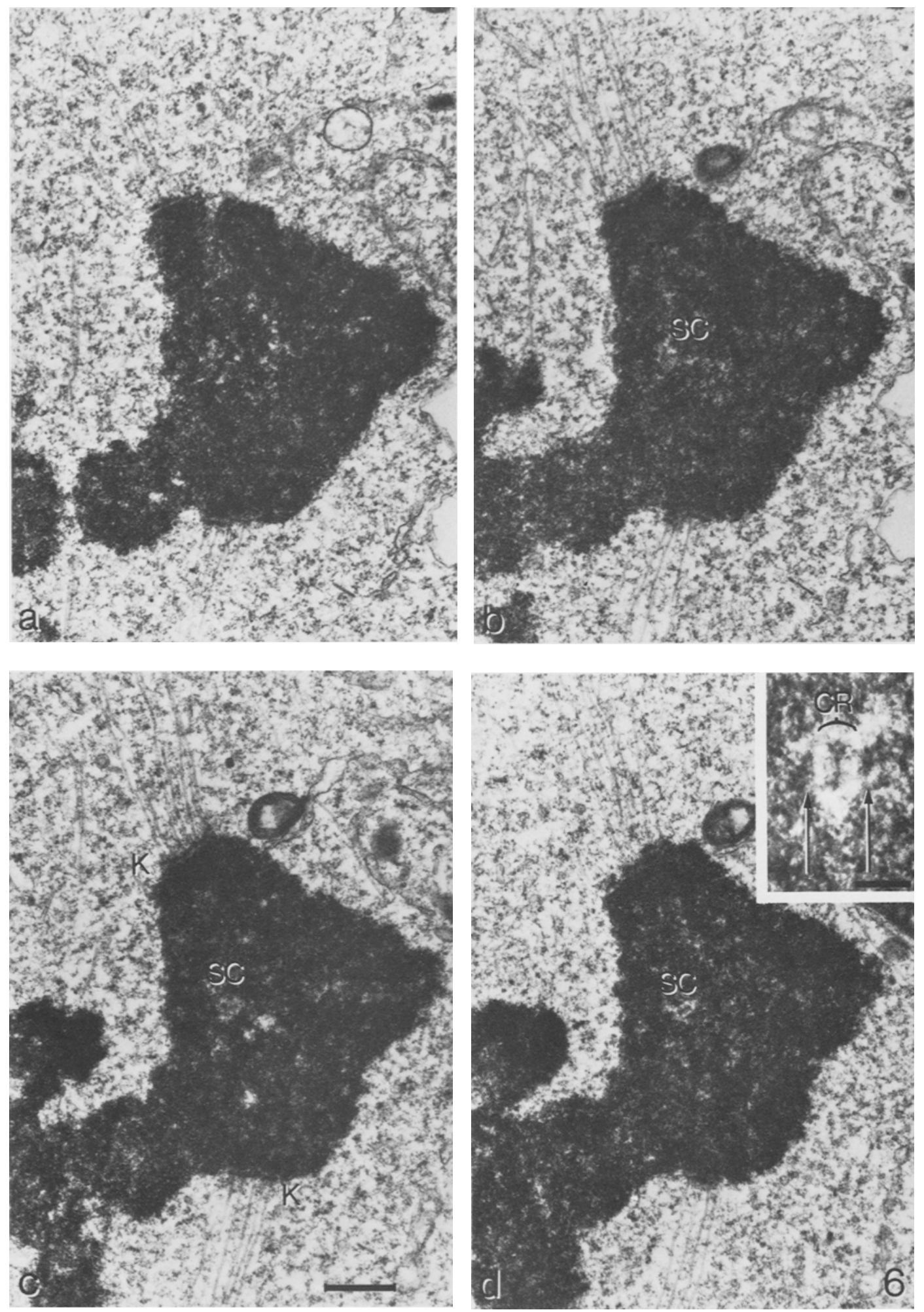

Figure 6. Four consecutive sections through a bivalent at metaphase I (nucleus 45). Distinct bundles of microtubules are attached to the kinetochores $(K)$. The kinetochores of the two sister chromatids are confluent forming a straight laminated disc. A synaptonemal complex fragment (SC) is present in Figures $6 \mathrm{~b}-\mathrm{d}$. The insert in Figure $6 \mathrm{~d}$ is a high magnification of the complex fragment in Figure 6d. The central region (CR) is flanked by apparently normal lateral components (arrows). (Figures 6a-d: $\mathrm{Bar}=0.5 \mu \mathrm{m}$, insert: $\mathrm{Bar}=0.1 \mu \mathrm{m}$ ). 
ing was perpendicular to the spindle axis. In one of the cells, 46 regions of centromeric heterochromatin could be identified, but only one bivalent had undergone complete disjunction. Kinetochores of sister chromatids appear to be confluent, forming a crescent shaped structure. As illustrated in Figure 11 the centromeric heterochromatin and the kinetochores are partially enclosed by the chromatin proximal to the centromere region.

\subsection{Synaptonemal complexes}

\subsubsection{Prometaphase I}

A preliminary description of the synaptonemal complex in prometaphase I bivalents of human spermatocytes has been given in a previous publication (7). From 36 to 58 synaptonemal complex fragments per cell were reported for three prometaphase cells. Upon reexamination of these cells, some aggregated synaptonemal complex fragments which in the previous investigation were recorded as individual fragments have been reinterpreted as small aggregates and have therefore in the present analysis been counted as single units (Table I).
The ultrastructure of the majority of the fragments at prometaphase is almost identical to that of pachytene synaptonemal complexes with distinct central regions and recognizable lateral components (Figure 1). In addition some fragments were identified which probably were in the process of disintegration. Frequently, the synaptonemal complex fragments are located approximately equidistant from the kinetochores of the homologues indicating that the complex fragments still retain their original position between the homologues of the bivalents. As illustrated in Table I, elimination of complex fragments from the bivalents has, however, started. In the three prometaphase cells analyzed, from 22 to 43 single complex fragments or small aggregates of fragments were located inside bivalents whereas from 2 to 14 were located at bivalent borders. Aggregated synaptonemal complex fragments were only in one nucleus found in the nucleoplasm outside a bivalent (nucleus 19, Table I). Nuclei 18 and 19 (Tables I and II) appear to be more advanced in development than nucleus 6 as judged by the smaller number of fragments inside the bivalents. In nuclei 18 and 19 , shedding of synap-

Table I

Number and total length of synaptonemal complex fragments at prometaphase, metaphase and early anaphase.

\begin{tabular}{|c|c|c|c|c|c|c|c|c|}
\hline \multirow[t]{2}{*}{$\begin{array}{l}\text { Nucleus } \\
\text { number }\end{array}$} & \multirow[t]{2}{*}{ Stage } & \multicolumn{2}{|c|}{$\begin{array}{c}\text { SC fragments inside } \\
\text { bivalents }\end{array}$} & \multicolumn{2}{|c|}{$\begin{array}{l}\text { SC fragments at } \\
\text { bivalent border }\end{array}$} & \multicolumn{2}{|c|}{$\begin{array}{l}\text { SC fragments } \\
\text { outside bivalents }\end{array}$} & \multirow{2}{*}{$\begin{array}{c}\text { Total } \\
\text { SC } \\
\text { length } \\
\mu \mathrm{m}\end{array}$} \\
\hline & & Number & $\begin{array}{c}\text { Total length } \\
\mu \mathrm{m}\end{array}$ & Number & $\begin{array}{c}\text { Total length } \\
\mu \mathrm{m}\end{array}$ & Number & $\begin{array}{c}\text { Total length } \\
\mu \mathrm{m}\end{array}$ & \\
\hline 6 & prometaphase & 43 & 13.1 & 2 & 0.6 & 0 & - & 13.7 \\
\hline 18 & prometaphase & 22 & 10.7 & 14 & 8.0 & 0 & - & 18.7 \\
\hline 19 & prometaphase & 23 & 12.6 & 7 & 4.1 & 2 & 1.1 & 17.8 \\
\hline 45 & metaphase & 5 & 1.3 & 9 & 9.1 & 2 & 1.2 & 11.6 \\
\hline 46 & metaphase & 3 & 1.7 & 7 & 7.0 & 4 & 9.0 & 17.7 \\
\hline 51 & metaphase & 7 & 3.1 & 12 & 7.4 & 1 & 2.1 & 12.6 \\
\hline 76 & metaphase & 9 & 6.1 & 4 & 2.6 & 4 & 12.5 & 21.2 \\
\hline 78 & metaphase & 5 & 3.1 & 5 & 2.4 & 11 & 19.8 & 25.3 \\
\hline 79 & metaphase & 8 & 3.7 & 4 & 5.9 & 6 & 13.2 & 22.8 \\
\hline 52 & early anaphase & 0 & - & 0 & - & - & - & - \\
\hline 53 & early anaphase & $4^{+}$ & 1.1 & 0 & - & - & - & - \\
\hline
\end{tabular}

+) One bivalent with 3 fragments and one with one fragment.

8) Mean $=17.9 \pm 4.4 \mu \mathrm{m}$ 

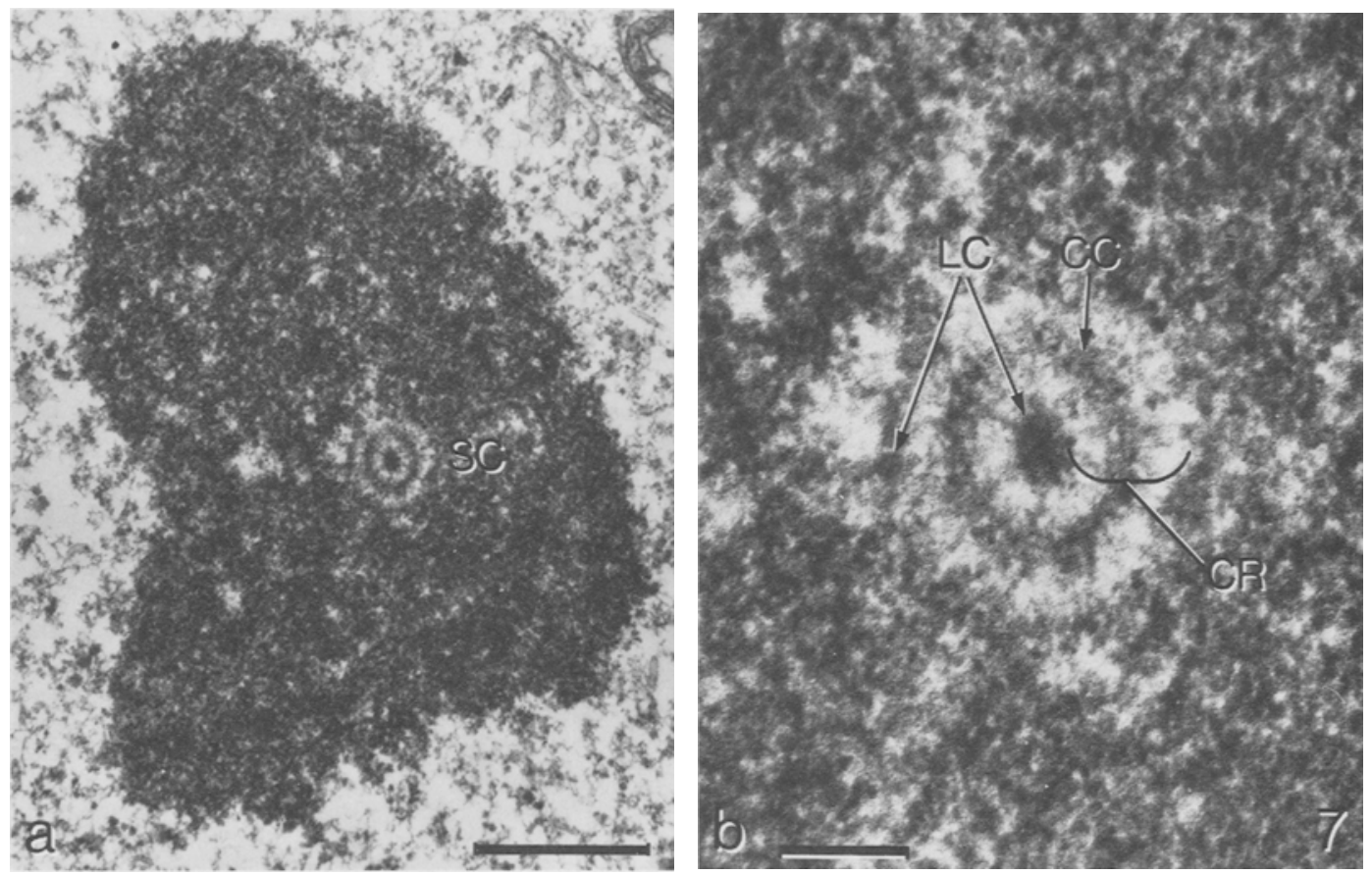

Figure 7. A metaphase I bivalent (nucleus 46) with a circular synaptonemal complex fragment (SC) is shown in Figure 7a. Figure $7 \mathrm{~b}$ is a higher magnification of the fragment. Material of the same electron density as that of lateral components $(\mathrm{LC})$ is associated with the central region (CR). The ultrastructure of the central component is very similar to that of pachytene synaptonemal complexes. (Figure 7a: Bar $=0.5 \mu \mathrm{m}$, Figure $7 \mathrm{~b}: \mathrm{Bar}=0.1 \mu \mathrm{m}$ ).

\section{Table II}

Mean lengths of synaptonemal complex fragments at prometaphase, metaphase and anaphase.

\begin{tabular}{|c|c|c|c|c|c|c|c|c|c|c|}
\hline \multirow[t]{2}{*}{$\begin{array}{l}\text { Nucleus } \\
\text { number }\end{array}$} & \multirow[t]{2}{*}{ Stage } & \multicolumn{3}{|c|}{$\begin{array}{l}\text { Length of } \\
\text { SC fragments inside } \\
\text { bivalents }(\mu \mathrm{m})\end{array}$} & \multicolumn{3}{|c|}{$\begin{array}{c}\text { Length of } \\
\text { SC fragments at } \\
\text { bivalent border }(\mu \mathrm{m})\end{array}$} & \multicolumn{3}{|c|}{$\begin{array}{c}\text { Length of } \\
\text { SC fragments } \\
\text { outside bivalents }(\mu \mathrm{m})\end{array}$} \\
\hline & & Mean & s.d. & Range & Mean & \pm s.d. & Range & Mean & \pm s.d. & Range \\
\hline 6 & prometaphase & 0.3 & 0.2 & $0.1-0.8$ & 0.3 & 0.1 & $0.2-0.4$ & - & - & - \\
\hline 18 & prometaphase & 0.5 & 0.2 & $0.2-0.8$ & 0.6 & 0.3 & $0.1-1.0$ & - & - & - \\
\hline 19 & prometaphase & 0.6 & 0.3 & $0.2-1.1$ & 0.6 & 0.5 & $0.1-1.6$ & 0.5 & 0.9 & $0.4-0.6$ \\
\hline 45 & metaphase & 0.3 & 0.1 & $0.2-0.5$ & 1.0 & 1.2 & $0.3-4.1$ & 0.6 & 0.2 & $0.4-0.8$ \\
\hline 46 & metaphase & 0.6 & 0.1 & $0.4-0.7$ & 1.0 & 0.5 & $0.4-1.8$ & 2.3 & 2.3 & $0.3-6.2$ \\
\hline 51 & metaphase & 0.4 & 0.2 & $0.2-0.8$ & 0.7 & 0.5 & $0.2-1.8$ & 2.1 & - & - \\
\hline 76 & metaphase & 0.7 & 0.3 & $0.2-1.0$ & 0.7 & 0.2 & $0.3-0.9$ & 3.1 & 2.2 & $1.1-6.6$ \\
\hline 78 & metaphase & 0.6 & 0.1 & $0.4-0.8$ & 0.5 & 0.1 & $0.4-0.6$ & 1.8 & 1.3 & $0.3-3.9$ \\
\hline 79 & metaphase & 0.5 & 0.2 & $0.3-0.8$ & 1.5 & 1.0 & $0.3-3.0$ & 2.2 & 1.2 & $0.6-4.1$ \\
\hline 52 & early anaphase & - & - & - & - & - & - & - & - & - \\
\hline 53 & early anaphase & 0.3 & 0.1 & $0.1-0.4$ & - & - & - & - & - & - \\
\hline
\end{tabular}




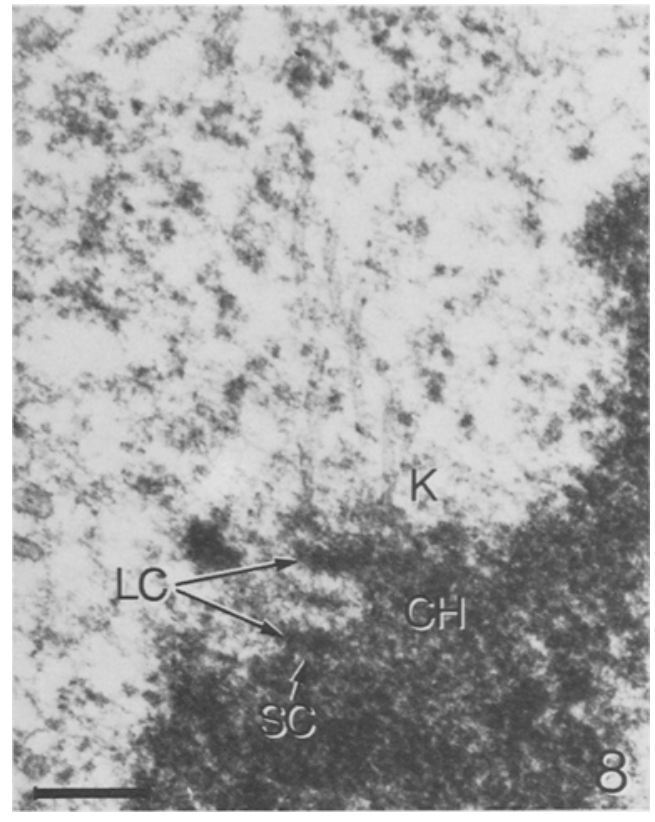

Figure 8. Micrograph of a synaptonemal complex fragment (SC) which is being eliminated from a bivalent. The fragment is partially embedded in the centromeric heterochromatin $(\mathrm{CH})$ near the kinetochore (K). Apparently normal lateral components (LC) are associated with the central region of the fragment. (Bar $=0.5 \mu \mathrm{m})$. tonemal complex fragments from the bivalents is in progress as illustrated by the larger fragment length (or combined length of aggregated complex fragments) and the presence of fragments at bivalent borders and in the nucleoplasm (only in nucleus 19).

\subsubsection{Metaphase I}

At metaphase I, the elimination of synaptonemal complex fragments from the bivalents is almost completed. The fragments inside bivalents constitute only $17 \%$ of the total fragment length whereas $31 \%$ are located at bivalent borders and $52 \%$ completely free in the nucleoplasm. As illustrated in Figures 4 and 6, apparently intact complex fragments with distinct central regions and lateral components are still present in the bivalents at this stage. Fragments forming closed or nearly closed circular structures were frequently seen (Figure 7). In the nucleoplasm, synaptonemal complex fragments formed various aggregates ranging from parallelly aranged complexes (Figure 9) to irregularly shaped compound structures (Figure 10).

In several cases, the complex fragments appeared to be eliminated in an intact form from

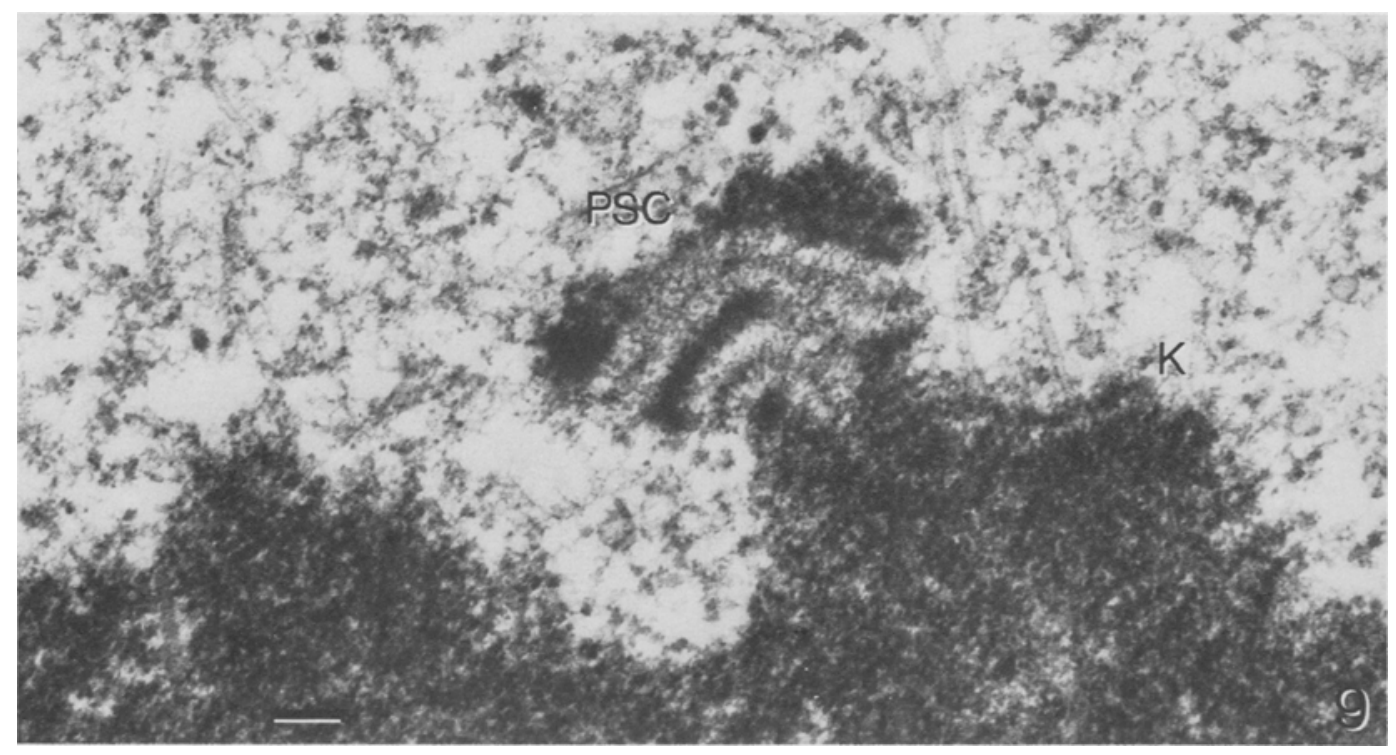

Figure 9. Micrograph of a synaptonemal polycomplex (PSC) at metaphase $\mathrm{I}$. The polycomplex is associated with the peripheral part of the bivalent adjacent to the kinetochore $(\mathrm{K})$. $(\mathrm{Bar}=0.1 \mu \mathrm{m})$. 

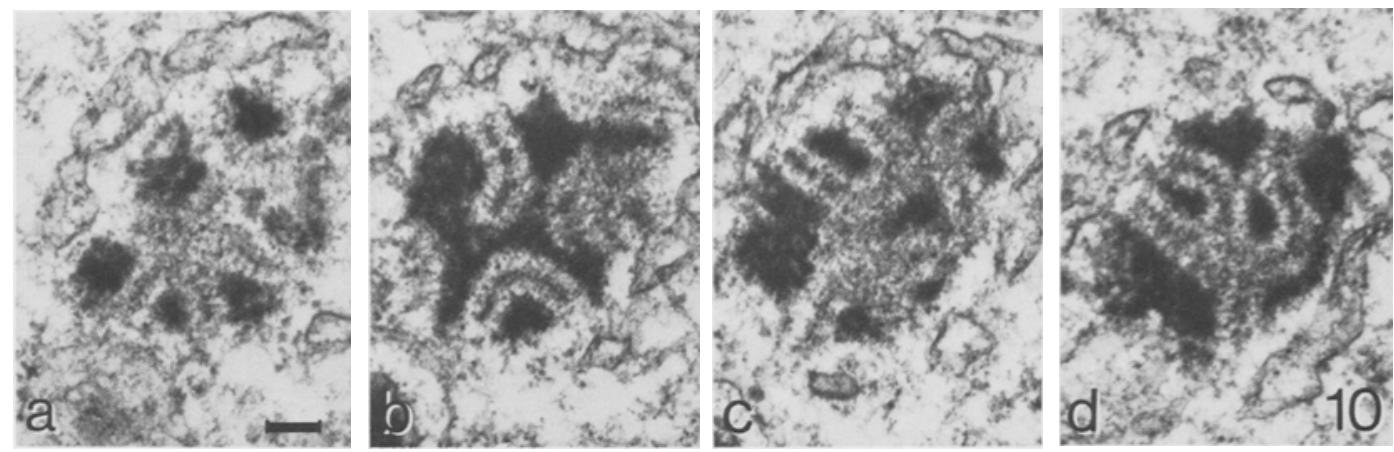

Figure 10. Four consecutive sections through a synaptonemal polycomplex at metaphase I. The polycomplex is free in the nucleoplasm and consists of fused, curved fragments of the central region embedded in a matrix with an electron density similar to that of lateral components. $(\mathrm{Bar}=0.1 \mu \mathrm{m})$.

the bivalent, either through the centromeric heterochromatin (Figures 5, 8 and 9) or between the two homologues (Figure 5), Other fragments in the bivalents showed indication of a disintegration (Figure 6).

\subsubsection{Early anaphase I}

In the two early anaphase I nuclei (nuclei 52 and 53), four small synaptonemal complex fragments were found; three fragments inside one bivalent and one in another bivalent of the same nucleus. Synaptonemal complex frag- ments were not found either at chromosome borders or in the nucleoplasm. It is, however, possible that cytoplasmic complex fragments may have escaped detection as only those sections containing chromosomes or bivalents were photographed and the entire cell thus not examined. In a recent report SOLARI and VILAR (21) showed that the synaptonemal polycomplexes persist in the cytoplasm during anaphase $I$, telophase I, up to and including the interphase of the secondary spermatocytes. During and after the second meiotic division, synaptonemal polycomplexes were not observed.
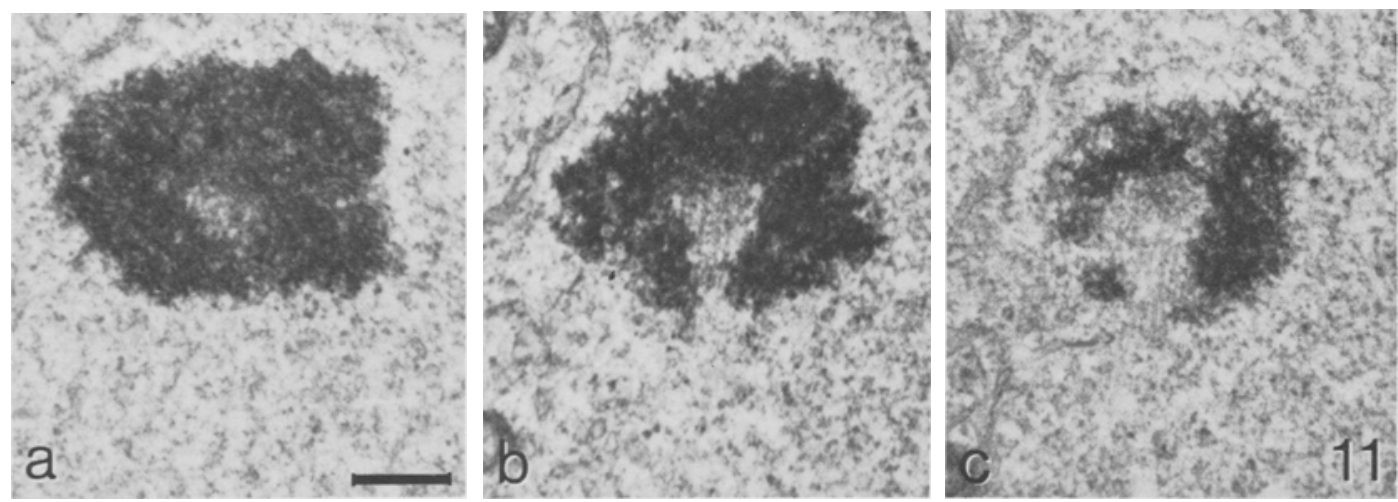

Figure 11. Three consecutive sections through the kinetochore at a chromosome of anaphase I. The kinetochore is located in an invagination of the chromatin. ( $\mathrm{Bar}=0.5 \mu \mathrm{m})$. 


\section{DISCUSSION}

\subsection{General aspects}

The present study has clearly demonstrated that each of the four chromatids of a bivalent at promethaphase I possess a fully differentiated kinetochore. The kinetochores of the two sister chromatids frequently appear to be separate at prometaphase I while at metaphase and anaphase the kinetochores of sister chromatids are confluent.

The number of kinetochores per prometaphase I bivalent has been debated repeatedly in classical light microscopical investigations. SCHRADER (19) concluded that in Amphiuma and in Tradescantia, 4 sspindle spherules" were present per bivalent, whereas DARLINGTON (1) concluded that the evidence for a double centromere region of each chromosome was uncertain in most organisms. Ultrastructural observations have supported SCHRADER's proposal that each chromatid has its own kinetochore. In Urechis eggs the length of the kinetochore at metaphase I and anaphase I was twice the length of kinetochores at metaphase and anaphase II (11), and in Pales, MULLER (14) reported that kinetochores of prometaphase chromosomes were double. A bipartite organization of kinetochores at metaphase I and anaphase I was also reported in Neottiella (23). In agreement with the present results from human spermatocytes, MULLER (14) noted that the kinetochore profile at prometaphase I was crescent shaped, at metaphase I straight and at anaphase I crescent shaped and partly surrounded by chromatin.

The reconstructions have demonstrated that the bivalents at prometaphase I are highly condensed with the homologous centromere regions often closely associated. Complete separation of the two centromere regions does not occur before metaphase I is reached. This result is in constrast to the generally accepted view that repulsion of homologous regions not stabilized by chiasmata takes place at diplotene and is maintained through diakinesis up to metaphase I. In maize (3) and Scaptericus (22) reconstructions of diplotene bivalents did not reveal repulsion of homologous regions from which the synaptonemal complex had been shed. The ultrastructure of the bivalents at diplotene and diakinesis in human spermatocytes has not yet been analyzed in detail and information on the behaviour of the centromere region during the pachytene-prometaphase interval is therefore not available at present.

\subsection{Synaptonemal complexes}

The present study has revealed that in human spermatocytes 7 to $8 \%$ of the synaptonemal complex length present at pachytene is retained as fragments in the bivalents up to metaphase $\mathrm{I}$. At prometaphase, the complex fragments are primarily located inside the bivalents and appear ultrastructurally very similar to pachytene synaptonemal complexes although with less distinct lateral components. At metaphase I, most of the synaptonemal complex fragments are present at bivalent borders or in the nucleoplasm as small aggregates of rearranged fragments. It is thus evident that the majority of the synaptonemal complex fragments are expelled from the bivalents prior to or during the organization of the metaphase plate, either as intact fragments or following a reorganization of the synaptonemal complex subunits. At early anaphase I, very few complex fragments or aggregates were found in or associated with the bivalents.

The data presented in Table I show that the amount of synaptonemal complex is of the same order of magnitude in both prometaphase and metaphase cells. This indicates that the polycomplexes seen in the nucleoplasm originate from synaptonemal complex fragments expelled from the bivalents and not as a result of de novo synthesis of synaptonemal complex subunits.

It has previously been proposed that the retained synaptonemal complex fragments at prometaphase I in human spermatocytes are the ultrastructural counterparts of chiasmata (7). This contention has gained further support by the correspondance between the number of these fragments and the number of chiasmata in diakinesis nuclei, seen in the light microscope. HULTÉN (9) reported that the mean chiasma count per cell was $50.6 \pm 3.9$ (range 43-60) which is slightly higher than the number of synaptonemal complex fragments at prometa- 
phase I $(32,36$ and 43$)$. The number of complex fragments is probably underestimated since disintegration and fusion of synaptonemal complex fragments has already begun at this stage. The mean synaptonemal complex length (which includes all fragments and polycomplexes) of the nine prometaphase and metaphase I cells, is $17.9 \mu \mathrm{m}$ which corresponds to a mean synaptonemal complex length per chias$\mathrm{ma}$ of $0.35 \mu \mathrm{m}$.

In a recent study on human spermatocytes, SOLARI and VILAR (21) reported a similar elimination of complex fragments from prometaphase I bivalents, the expelled segments forming small polycomplexes. The maximum length per nucleus of all synaptonemal complexes constituting the polycomplexes was 6.4 $\mu \mathrm{m}$ which corresponds to a synaptonemal complex length per chiasma of only $0.13 \mu \mathrm{m}$. SOLARI and VILAR arrived at the conclusion that it is unlikely that the synaptonemal complex fragments represent chiasmata.

Retained fragments of synaptonemal complexes have been described in a number of organisms during diplotene $(3,5,10,20,22,24$, 27). In Sordaria (27), Neurospora (5) and Ascaris (10) most of the fragments were associated with a recombination nodule and in the first two organisms the total number of nodules equaled the number present at pachytene. In all other organisms where the diplotene stage has been studied, nodules have not been reported to be a constituent of the fragments. In maize (3) the number of fragments is twice as large as the number of chiasmata, while in Scaptericus (22) only one fragment is present per bivalent. The diplotene stage is in this organism followed by a diffuse stage apparently without synaptonemal complex fragments. In Neottiella (24), fragments were not found in diakinesis nuclei, while in maize Gillies (3) noted gaps in the chromatin of diakinesis bivalents resembling the central region of the complex, but concluded that the constituents of the synaptonemal complex were absent. In mouse SoLARI reported (20) that synaptonemal complex fragments were replaced by chromatin bridges during diplotene.

In addition to human spermatocytes, synaptonemal complex fragments have been found at metaphase I in pigeon (15) and in the grasshopper Chorthippus (12). It is evident that more work involving reconstructions of diplotene and diakinesis nuclei is required before definite conclusions can be drawn concerning the ultrastructure of chiasmata and the function of the synaptonemal complex fragments at prometaphase $\mathrm{I}$.

\section{ACKNOWLEDGEMENTS}

It is a pleasure to acknowledge the expert technical assistance of JEAN SAGE, ANN-SofI Steinholtz, Nina Rasmussen and Lena Kongsrud. We also wish to thank Prof. D. voN WETTSTEIN for his critical review of the manuscript. The work was supported by grant 202-76-1 BIO DK from the Commission of the European Communities.

\section{REFERENCES}

1. Darlington, C. D.: Recent advances in cytology. 2nd ed. Churchill, London 671 pp. (1937)

2. GASSNER, G.: Synaptinemal complexes in the achiasmatic spermatogenesis of Bolbe nigra Giglio-Tos (Mantoidea) Chromosoma (Berl.) 26, 22-34 (1969)

3. GiLlies, C. B.: An ultrastructural analysis of chromosomal pairing in maize. Compt. Rend. Trav. Lab. Carlsberg 40, 135-161 (1975)

4. Gillies, C. B.: Synaptonemal complex and chromosome structure. Ann. Rev. Genet. 9, 91-109 (1975)

5. Gillies, C. B.: The relationship between synaptonemal complexes, recombination nodules and crossing over in Neurospora crassa bivalents and translocation quadrivalents. Genetics (in press)

6. HOLM, P. B. \& S. W. Rasmussen. Human meiosis I. The human pachytene karyotype analyzed by three dimensional reconstructions of the synaptonemal complex. Carlsberg Res. Commun. 42, 283-323 (1977)

7. Holm, P. B. \& S. W. Rasmussen: Three-dimensional reconstruction of meiotic chromosomes in human spermatocytes. In: A. de la Chapelle \& $\mathbf{M}$. Sorsa, eds., Chromosomes Today 6, 83-93 (1977)

8. Holm, P. B. \& S. W. Rasmussen: Human meiosis III. Electron microscopical analysis of chromosome pairing in an individual with a balanced translocation 46, XY, $t(5 p \div ; 22 p+)$. Carlsberg Res. Commun. 43, 329-350 (1978) 
9. Hultén, M.: Chiasma distribution at diakinesis in the normal human male. Hereditas $76,55-78$ (1977)

10. KUndu, S. C. \& Yu. F. Bogdanov: Ultrastructural studies of late meiotic prophase nuclei of spermatocytes in Ascaris suum. Chromosoma (Berl.) (in press)

11. LUYKX, P.: The structure of the kinetochore in meiosis and mitosis in urchin eggs. Exptl. Cell Res. 39, 643-657 (1965)

12. Moens, P. B.: Multiple core complexes in grasshopper spermatocytes and spermatids. J. Cell Biol. 40, 542-551 (1969)

13. Moses, M. J.: Synaptinemal complex. Ann. Rev. Genet. 2, 363-412 (1968)

14. MOLLER, W.: Elektronmikroskopische Untersuchungen zum Formwechsel der Kinetochoren während der Spermatocytenteilungen von Pales ferruginea (Nematocera). Chromosoma (Berl.) 38, 139-172(1972)

15. Nebel, B. R. \& E. M. Coulon: The fine structure of chromosomes in pigeon spermatocytes. Chromosoma (Berl.) 13, 272-29l (1962)

16. Rasmussen, S. W.: The meiotic prophase in Bombyx mori females analyzed by three dimensional reconstructions of synaptonemal complexes. Chromosoma (Berl.) 54, 245-293 (1976)

17. Rasmussen, S. W.: The transformation of the synaptonemal complex into the "elimination chromatin" of Bombyx mori oocytes. Chromosoma (Berl.) 60, 205-221 (1977)

18. Rasmussen, S. W. \& P. B. Holm. Human meiosis II. Chromosome pairing and recombination no- dules in human spermatocytes. Carlsberg Res. Commun. 43, 275-328 (1978)

19. SCHRADER, F.: The structure of the kinetochore at meiosis. Chromosoma (Berl.) 1, 230-237 (1939)

20. SOlARI, A. J.: The behaviour of chromosomal axes during diplotene in mouse spermatocytes. Chromosoma (Berl.) 31, 217-230 (1970)

21. Solari, A. J. \& O. Vilar: Multiple complexes in human spermatocytes. Chromosoma (Berl.) 66, $331-340$ (1978)

22. SOTELo, R. J., R. B. Garcia, \& R. WetTSTEIN: Serial sectioning study of some meiotic stages in Scaptericus borrelli (Grylloidea). Chromosoma (Berl.) 42, 307-333 (1973)

23. WestergaArd, M. \& D. von Wettstein: The nucleolar cycle in an ascomycete. Compt. Rend. Trav. Lab. Carlsberg 37, 195-238 (1970)

24. Westergaard, M. \& D. von Wettstein: Studies on the mechanism of crossing-over IV. The molecular organization of the synaptinemal complex in Neottiella (Cooke) Saccardo (Ascomycetes). Compt. Rend. Trav. Lab. Carlsberg 37, 239-268 (1970)

25. Westergatrd, M. \& D. von Wettstein: The synaptinemal complex. Ann. Rev. Genet. 6, 71-110 (1972)

26. WetTStein, D. von: The synaptinemal complex and four-strand crossing over. Proc. Nat. Acad. Sci. USA 68, 851-855 (1971)

27. ZiCKLER, D: Development of the synaptonemal complex and the "recombination nodules" during meiotic prophase in the seven different bivalents of the fungus Sordaria macrospora Auersw. Chromosoma (Berl.) 61, 289-316 (1977) 